\title{
Regional integration and health policies
}

This supplement has resulted from the MERCOSUR Forum on Regional Integration and Health Systems, organized by the Network for Health Systems and Services Research in the Southerrn Cone of Latin America in March 2006 in Rio de Janeiro, Brazil. The regional integration issue has been increasingly present on the economic and political agenda of Latin American countries, since in a context of asymmetrical globalization the continent's sub-regions have attempted to strengthen their ties in order to gain a more favorable position in international negotiations. Thus, they not only change the rules of the trade game, but also produce social changes, including those related to health policies and the right to health care.

The objective image of the regional integration is still not clear and has not been discussed by the overall population, but rather at the inter-governmental level, with varying speeds and approaches in the processes, according to changes in government administrations and the existence of alliances or conflicts between member countries. Integration has progressed nevertheless, but in relation to health policies and systems, until recently the possibilities and risks have not been object of research.

Latin Americans live in the most unequal region in the world, where a feeling of regional unity built by a common history and ideals (especially beginning with the 19th century wars of independence) coexists with low integration within the countries, marked by class and ethnic barriers. This raises important challenges for the concept of integration, the definition of its actors and beneficiaries, and the tools for achieving it with broad social participation, respecting our continent's rich cultural variety and shared democratic values. It establishes challenges for promoting an integration process with a socially inclusive economic development model that reduces the asymmetries between the countries and attenuates the profound inequalities within each country, promoting social cohesion.

The articles here examine the Latin American integration processes in light of the European experience, with a focus on health policies and human resouces in health, in addition to reflecting on the uneven advances in the integration process and its conditioning factors. The articles on the European process analyze the repercussions of common markets on the health sector and highlight themes for health research in our region.

A set of studies discusses the current MERCOSUR negotiations in the field of social and health policies, current harmonization processes, and dilemmas to build democratic institutions with the recognition and guarantee of social rights. Various articles discuss human resources in health in the integration processes in terms of allocation needs, cross-border migration, and research challenges. Another set of articles focuses on population dynamics, resources, flows, and guarantees of the right to health care in border areas, since these areas anticipate the future effects of integration.

We hope to contribute with this supplement to the indispensable debate on the political and social dimensions of MERCOSUR, beyond the emphasis on the economic sphere in the shaping processes ruling of common markets. The Research Agenda elaborated by Forum participants and presented in the Report at the end of the supplement lists key political, socio-cultural, organizational, and techni$\mathrm{cal} /$ operational themes for conducting research and continuing this debate.

Ligia Giovanella

Escola Nacional de Saúde Pública Sergio Arouca, Fundação Oswaldo

Cruz, Rio de Janeiro, Brasil.

Network for Health Systems and Services Research in the Southern

Cone of Latin America, Rio de Janeiro, Brazil.

giovanel@ensp.fiocruz.br
Delia M. Sánchez

Grupo de Estudios en Economía, Organización y Políticas de Salud, Montevideo, Uruguay.

Network for Health Systems and Services Research in the Southern Cone of Latin America, Montevideo, Uruguay.

dibarsan@adinet.com.uy 